\title{
Live and Let Die: On the Management of Creativity
}

Michael Hartmann, Désirée Laubengaier and Kai Foerstl

\author{
"Having ideas is like having chessmen moving forward; they \\ may be beaten, but they may start a winning game." \\ Johann Wolfgang von Goethe \\ Statesman and writer
}

\begin{abstract}
Literature has pointed to the importance of feedback on creative ideas in innovation management processes. However, little is known about the practices that constitute the feedback process and their effect on employees' future willingness to consistently and recurrently contribute with creative ideas to organized innovation management efforts. In this research, we draw on data from a single case study at a German multinational manufacturing firm. We show the flip side of managerial attempts to provide feedback and foster employees' creative output. In particular, we identify distinct practices organizational actors employ along the sequence of idea generation, elaboration, championing, and implementation, and find that the practices can turn organized innovation management efforts into a political process. Furthermore, we present a virtuous and a vicious circle of managerial attempts to manage creativity in innovation processes. In doing so, we highlight the value of taking a practice lens to better understand the challenges in organized innovation management efforts and propose future research in other contexts. We suggest that managers should flexibly design organized innovation management processes to account for radical ideas and to pay close attention to a coherent communication when providing feedback and encouraging employees to contrive creative ideas. Our work contributes to the body of research on innovation management by shedding light on the dark side of organized innovation management efforts.
\end{abstract}

\section{Introduction}

In order to absorb and leverage the potentials from most recent technological developments (for example, digitalization, advanced robotics and additive production techniques), firms must reach out to their employees and their creative minds. That way firms generate and exploit ideas how to best connect novel outside technological developments with existing internal processes in innovation management efforts. Hence, fostering employees' willingness to come up with creative ideas is considered to be an integral part of innovation processes (Garud et al. 2013), and organizations put significant effort in managing creativity as a key element of their innovation management agendas.

Because "all novel ideas must be critically revised before they come to fruition" (Garud et al., 2013: 783), scholarly work highlights the role of managers' feedback on creative ideas in innovation management processes (George, 2007). Researchers point to the fact that feedback not only influences the development of creative ideas to turn them into marketable products and services (Harrison and Rouse, 2015), but also determines actors' willingness to come up with creative ideas and to participate pro-actively in future innovation processes (Amabile, 1988). The burden literature on creativity has shown that feedback has a significant and yet complex influence on creativity. However, research dealing with the mechanisms and underlying practices through which such influences occur remains sparse (Anderson et al. 2014; Harrison and Rouse, 2015). This is surprising given that the underlying managerial practices, i.e. actors' doings, are a key to explain the success of innovation management efforts and, consequently, an organization's ability to constantly innovate.

Accordingly, the objective of this paper is to provide insights on managerial practices that unfold as ideas emerge, are developed, and are implemented systematically within firms. Particularly, we explore managerial practices along the journey sequence of idea generation, idea elaboration, idea championing, and idea implementation (Perry-Smith and Mannucci, 2017), thus taking into account effects and consequences for innovation management. Thereby, we aim at answering 


\section{Live and Let Die: On the Management of Creativity}

\section{Michael Hartmann, Désirée Laubengaier and Kai Foerstl}

the following research question: How do actors respond to feedback on their creative work and how does that feedback interlink with structured firm innovation management processes? To do so, we draw on data from a longitudinal case study at a German multinational manufacturing firm, and empirically examine structural mechanisms and managerial practices that influence creative actors on their idea journey.

In doing so, we contribute to the existing innovation management and creativity literature by revealing a flip side of organized innovation management efforts, and how managers reverse attempts to foster creative output for innovations into political actions, which ultimately hamper creative output. We further contribute to research by presenting how either a virtuous or vicious circle impacts an organization's ability to innovate, and unfolds in the management of creativity. Additionally, this study provides various practical insights that can help organizations to improve their innovation management efforts by revealing practices that managers may use in the context of creativity and innovation.

In the remainder of this article, we first briefly explore the concept of creativity and its importance in innovation processes. We then show the current understanding of the influence of feedback on creativity, with both positive and negative impacts. After describing the method applied, we then present the findings of our study. In the final section, we discuss the results and explicate implications for academia and management alike.

\section{Related Literature and Conceptual Background}

Creativity is defined as "the production of novel and useful ideas by an individual or small group of individuals working together" (Amabile, 1988: 126), and is considered an important source of competitive advantage (Anderson et al., 2014). Among other factors, performance evaluation and feedback have been found to play a pivotal role for creativity (George, 2007). First, it greatly contributes to shaping creative prototypes (Harrison and Rouse, 2015), and thus, to the possibility of implementing a creative idea. Second, it influences actors' future creative performance (Amabile, 1988).

With regard to the latter, research has pointed to the role of managers as follows (see: George, 2007). For example, leaders can foster creativity through providing a supportive context, which can be accomplished by providing developmental feedback, i.e. informal feedback that points to improvement without using pressure. Feedback from managers, if perceived as useful, fosters individuals' creativity, especially when they are unsatisfied with their work environment. There is also a relationship between the provision of feedback and the presence of creative co-workers which, taken together, fosters the production of creative output as well.

The vast amount of literature dealing with feedback and creativity has deeply contributed to a better understanding of the relationship between feedback and creative performance. However, with regard to innovation processes in organizations, managerial feedback must also be understood as a way of managing innovations (Anderson et al., 2014), entailing decisions based on multiple criteria for whether or not to pursue proposed (creative) ideas, or to modify them. For example, research emphasized that creative ideas may be produced by employees, but are not necessarily implemented as intended or are even rejected, when decision-making boards can choose between different ideas to be realized (Baer, 2012; Piezunka and Dahlander, 2019). Consequently, managers face the challenge of promoting the production of creative output as part of their innovation management efforts, along with also revising and rejecting (auspicious) proposed ideas.

To get a more nuanced view on the challenges that idea inventors and decision makers face when dealing with creativity and feedback in innovation processes, PerrySmith and Mannucci (2017) conceptualize that ideas take a journey -from conception to (non-)completion. Remarkably, research taking a processual view (Fortwengel et al., 2017) examining the managerial practices during the journey ideas take, and how feedback receivers respond to feedback givers at different stages of the journey, remains scarce (Anderson et al., 2014). This is surprising given that creativity can only be understood in relation to an evaluated outcome that is negotiated in a process of social interaction, and that is likely to differ at various stages along the journey an idea takes. Furthermore, practices that come into play during such social interactions are constitutive for a work environment that largely influences organizational members' creativity performance.

Therefore, in this work, we draw on innovation management literature as well as on literature discussing the nature and role of feedback for creativity in innovation processes, and ask how actors respond to feedback on their creative work. Our aim is to identify managerial practices as well as organized innovation 


\title{
Live and Let Die: On the Management of Creativity
}

\author{
Michael Hartmann, Désirée Laubengaier and Kai Foerstl
}

management efforts that generate effects on employees, thereby pointing to potential challenges of processing creative ideas in an organizational context.

\section{Research Methods}

\section{Empirical approach and case description}

As we approached a new research topic for this paper, we decided for a qualitative-empirical research design (Yin, 2014). Such an approach is especially helpful to explore new research settings as it allows for uncovering causality, and goes beyond pure description, especially giving contextualization as possible. Even though existing research has provided a number of ideas on creativity, feedback and its connection with innovation management, the procedural perspective and its underlying mechanisms remain largely unexplored.

Following our research question, we sought to explore focal phenomena in the context in which they occur (Meredith, 1998), while being able to embrace existing findings and theory for a more focused exploration and substantiation of our results (Eisenhardt, 1989). In this regard, our research approach can best be described as theory elaboration (Vaughan, 1992), in contrast with theory testing (Popper, 1959), and grounded theory (Glaser and Strauss, 1967). In particular, we applied a qualitative, inductive research design comprising a longitudinal single case study with embedded multiple units of analysis (Yin, 2014). This approach allowed us to identify and explore relevant constructs and interrelationships, adding description and understanding of the interactions, meanings, and processes that constitute real-life settings (Gephart, 2004). Because the focal organization represents a case that made the phenomenon of interest accessible to investigation with the possibility of applying results to similar situations, and given the longitudinal design, a single-case study was appropriate for our empirical exploration (Mariotto et al., 2014; Siggelkow, 2007; Yin, 2014).

We approached the production facility of a world-wide manufacturing company headquartered in Germany, and observed the organization's operations for two years. Because the organization heavily relies on innovation management, the case was suitable to illuminate and extend relationships and logic around constructs, or in other words, the case was chosen for its potential contribution to conceptual advancement (Glaser and Strauss, 1967; Eisenhardt and Graebner, 2007; Siggelkow, 2007). Specifically, the production site installed several initiatives to encourage employees to come up with creative ideas that could enhance its innovation performance. Furthermore, the management team also looked for improvement initiatives that might be implemented across various production facilities. Interestingly, the management team also called for "unconventional" ideas in an attempt to promote not only incremental, but also radical change.

To conclude, the chosen case and the study design allow for relational inference rather than representational inference (Meredith, 1998), in that it is not meant to represent a random or stratified sample from a population (Flyvbjerg, 2006).

\section{Data collection and analysis}

The case study approach enabled the use of multiple methods of data collection for an in-depth exploration of the phenomenon within its natural setting (Meredith, 1998; Yin, 2014). We observed managers and employees involved in organized innovation management processes for two years. The approach allowed us to investigate the focal phenomena from different angles, tapping into a wide range of individual experiences and perspectives from numerous

Table 1. Data collection and analysis

\begin{tabular}{|c|c|c|}
\hline Data type & & Use in the analysis \\
\hline Interviews & 45 & $\begin{array}{l}\text { Familiarizing with the research context, capture managers' and employees } \\
\text { reflexive thoughts about innovation management efforts and feedback } \\
\text { processes. }\end{array}$ \\
\hline Field notes & 80 & $\begin{array}{l}\text { Identification of practices during fee dback interactions, } \\
\text { triangulation of findings from interviews and document analysis. }\end{array}$ \\
\hline Documents & 23 & $\begin{array}{l}\text { Familiarization with the research context, triangulation of } \\
\text { findings from the interviews and field notes. }\end{array}$ \\
\hline
\end{tabular}




\section{Live and Let Die: On the Management of Creativity}

\section{Michael Hartmann, Désirée Laubengaier and Kai Foerstl}

informants (Jick, 1979; Stuart et al., 2002). In particular, one researcher did on-site field work, accompanying actors during their daily routines, and attending ad hoc and frequently organized formal and informal gatherings where innovation activities played a major role. Furthermore, we carried out interviews and analyzed internal documents to facilitate the comparability of the findings, and to retain flexibility to probe deeper into emergent themes by eliciting examples, illustrations, and other insights (Barratt et al., 2011; Pratt, 2009). The interviews lasted 45 to 90 minutes. As a result, our data set consists of participant observation, interviews, documents, and field notes from numerous informal talks. The outlined approach enabled us to gain understanding of the phenomena through the views of those studied, and to examine and articulate processes (Pratt, 2009), including the meanings ascribed by informants to actions and settings (Gephart, 2004). When entering the empirical field, we applied a practice lens (Feldman and
Orlikowski, 2011), thus paying particular attention to the actors' and their regularities. The following table provides an overview of the data collected and its use in the analysis.

For data analysis, we followed the so-called "Gioia Methodology" (Gioia et al., 2013). Thus, we started with "open coding" and clustered our findings into "firstorder concepts". These concepts were grouped and clustered into theoretically abstracted "second-order themes". Finally, the themes were grouped into aggregated dimensions and later processed into a framework grounded in empirical data. The following figure shows the coding structure of our project.

During the process of coding the empirical material, we iteratively moved between (new) empirical data and (emergent) findings, and constantly checked for alternative explanations. When doing so, we applied an insider-outsider approach (Langley and Abdallah,

\section{First-Order Concepts}

$\underline{\text { Second-Order Themes }}$

Aggregated Dimensions

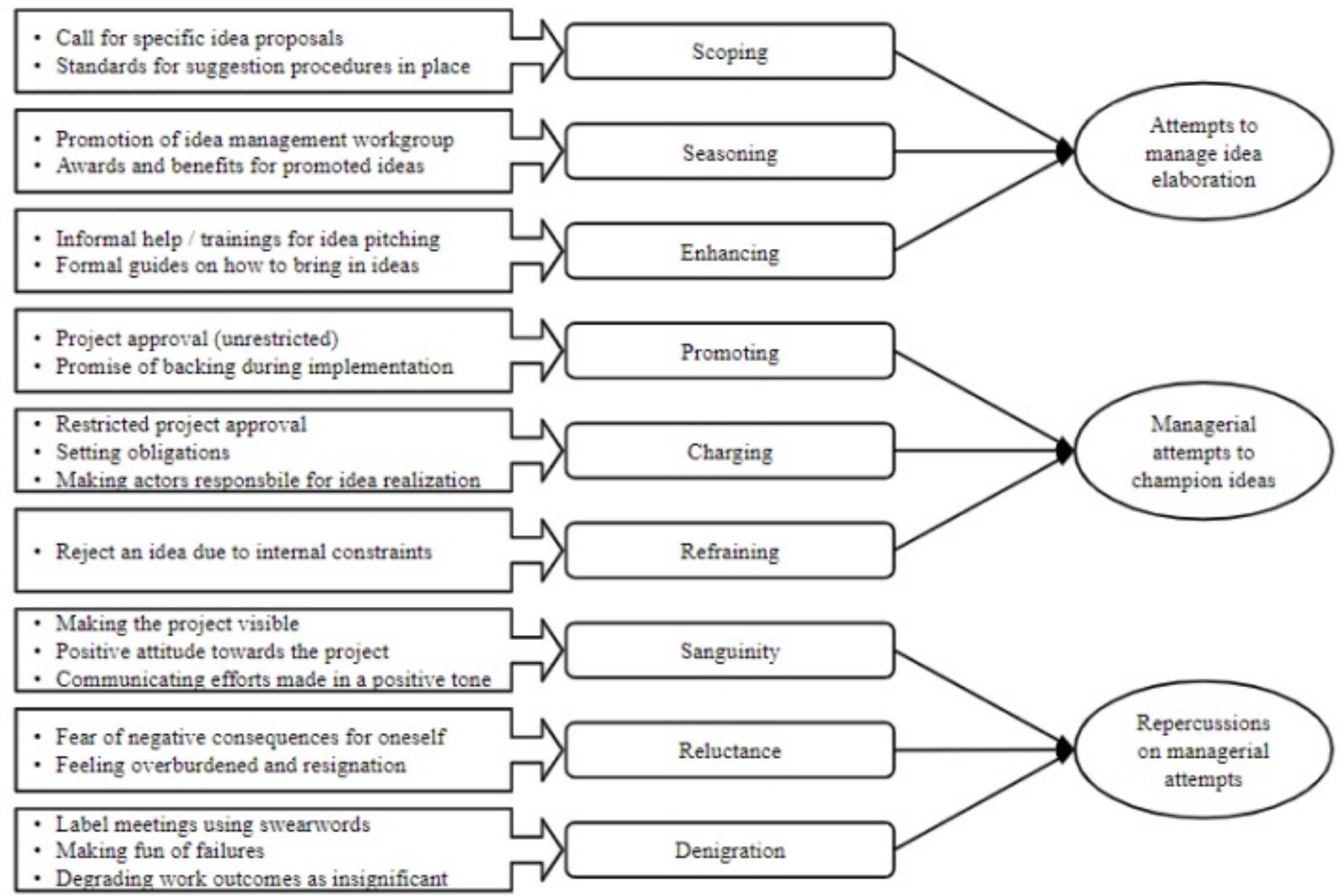

Figure 1. Coding-scheme of managerial attempts to manage creativity and outcomes 


\title{
Live and Let Die: On the Management of Creativity
}

\author{
Michael Hartmann, Désirée Laubengaier and Kai Foerstl
}

2011). That is, one author worked in the company as a guest researcher and got deeper involved in the observations made, while the other authors kept a more detached stance and played the role of a sceptic and critic when discussing results. Thus, data collection and analysis benefited from a balance between involvement and detachment.

We stopped gathering new data once no new results were obtained and saturation was reached (Glaser and Strauss, 1967). To increase reliability, we presented preliminary results to the company, checking their feedback.

\section{Findings}

We start this section by giving an overview of the main themes and second order concepts. In doing so, the idea journey (Perry-Smith and Mannucci, 2017) constitutes our conceptual foundation as we describe how managers try to foster the elaboration of ideas ("attempts to manage idea elaboration"), how they try to influence the development of ideas and communicate their decisions about project realization ("managerial attempts to championing ideas"), and how employees react to those managerial attempts in the innovation management process ("repercussions on managerial attempts"). The section closes with a theoretical framework that shows how the explored practices relate to each other and how the repercussions, in turn, influence employees' future engagement in organized processes where they can suggest their novel and (presumably) useful ideas.

\section{Attempts to manage idea elaboration: Scoping, \\ Seasoning, and Enhancing}

When entering the company, we recognized a plethora of approaches and instruments that were installed in the course of establishing a full blown innovation management system. In particular, the company's management was seeking to foster their innovation capabilities, which represented one of the primary corporate goals.

In order to foster innovativeness, the company incorporated specific actions to increase the amount of developed ideas that are potentially novel and useful, i.e. creative. First, managers tried to steer employees' attention to areas where innovative ideas are needed. Therefore, the company provided information via the intranet that delineates areas the company is looking for innovative ideas, and the company initialized idea workshops with a focus on specific problems or challenges the company faces. Furthermore, the company set up a guideline to describe in a detailed way what innovations should look like, for example, the need to reduce costs to a certain minimum amount. We summarize and define these activities as "scoping" because in employing these practices, the company assures that employees only suggest ideas that are within management's scope of interest.

In addition, the company offers specific training, for example, creativity techniques like "design thinking" and presentation skills, to enhance employees' abilities to develop and present their ideas properly. We summarize and term these efforts "enhancing" since they are designed to foster employees' capabilities to come up with creative ideas according to standards for innovative ideas set out by the company's management. Thus, "enhancing" and "scoping" are designed to work concordantly to foster the suggestion of ideas that are potentially novel and could be useful for the company. On the one hand, employees know exactly what an innovative idea should look like to be taken into account. On the other hand, employees are given help to elaborate their ideas so that they can convince the management team to implement them.

While the first two practices enhance employees' capabilities to suggest ideas, management also introduced provisions to foster employees' willingness to suggest ideas. For example, the company awards the best ideas, and rewards the suggestion of ideas by setting incentives. Idea workshops are advertised heavily, and management communicates the importance as well as the benefits novel ideas can have for the company, and for those who engage in suggesting ideas. We summarize and term these managerial attempts "seasoning" given the fact that they are designed to make participation in management's installed initiatives for idea management more attractive for employees.

The company's attempts to manage idea elaboration, i.e. "scoping", "enhancing", and "seasoning" foster the production of developed ideas to be presented in front of decision boards as part of an established innovation management process. This way they can compete for resources aimed at further development or implementation in the company.

\section{Managerial attempts to champion ideas: Promoting, Charging, Refraining}

Once ideas are developed, they are processed by institutionalized review boards. These boards consist of top and middle managers that are eligible to decide on whether ideas are pursued or not. Thus, these managers 


\title{
Live and Let Die: On the Management of Creativity
}

\author{
Michael Hartmann, Désirée Laubengaier and Kai Foerstl
}

decide on the realization of ideas and how they could be implemented. This includes making decisions on releasing resources that are needed to further develop an idea, i.e. money needed to build prototypes, reduced working time for employees to further pursue the idea, and idea implementation in the company itself. We observed three managerial practices when employees tried to convince the board of reviewers to support their idea. First, managers approved the idea as it was or requested only minimal changes. Simultaneously, managers communicated their appreciation of the efforts invested so far, and promised to help during further steps, thus making leeway for implementation of the idea. We termed this practice "promoting" since managers gave unrestricted approval and support of the idea.

When managers might be convinced by an idea, they can also give "conditional approval". They do so by putting the employee in charge of success for further developing or implementing the idea. As one manager put it when asked about the steering committee's decision philosophy when in doubt about the project's success:

\section{"He who suggests has to deliver." \\ (Member of the review board, Interview \#4)}

Furthermore, managers formulate restrictions for implementing the idea, articulate expectations towards the performance of the employee as the "project manager for the idea", and explicitly address issues to be resolved by the employee (for example, approval of expected values of key performance indicators). We termed this practice "charging" since the employee is set in charge for the success of the idea.

Finally, managers might also reject an idea by highlighting internal constraints. In doing so, they refer to scarce resources, expect the idea not to be implementable due to cultural and political boundaries (for example, other departments affected by the idea might resist it), or reject it due to other current priorities among management. We termed this practice "refraining" because managers simultaneously express their appreciation of the idea and possible value it has for the company, while rejecting it due to restrictions they cannot influence. While "promoting" and "charging" result in the implementation or further development of the idea, "refraining" ultimately leads to abandoning the idea as presented.

Repercussions on managerial attempts: Sanguinity,

\section{Reluctance, Denigration}

The explored managerial attempts at championing ideas lead to different repercussions related to employees. Once the presented idea is approved by the review board (that is, either through promoting or charging), the aim is to get the idea realized. Realization can take the form of producing a prototype or introducing new or adapted processes, respectively.

During the realization process, employees who originated the idea are typically highly committed to it and keen on bringing the project to a successful end. In particular, employees whose ideas are promoted by the review board feel emotionally involved and show a positive attitude towards the project. Besides working on the project, employees try to make the project visible by spreading the word about their activities. Similarly, efforts made in order to realize the project are communicated with a positive tone throughout the company. Since these employees feel deep emotional involvement and focus on the positive aspects of the project when talking about it, we termed this repercussion "sanguinity".

Quite the contrary, often people who are set in charge and held responsible for the success of the project, start fearing negative consequences. The fear of negative consequences refers to the success or failure of the project itself, overcoming resistant forces within the company, and potentially going worse off in balancing the demands, from daily work and being the project leader of their own idea. Given the multiple demands, employees can feel overburdened concerning their manager's expectations. When being confronted with the task of delivering a versatile set of prepared information designed to anticipate the success and impact of a project they came up with (ideated) to the management board, employees may even engage in resignation. We term this repercussion "reluctance" emphasizing an employee's negative attitude towards the project they are supposed to realize. For example, one employee reported:

\section{"I am frightened of the management board when it comes to project reviews." (Engineering Manager, Interview \#18)}

Finally, employees whose ideas have been rejected and will not be attempted or realized, question the process of innovation management. Although their ideas have been developed and presented according to the standards set up by the management team, the transparency of the rejection decision is called into 


\section{Live and Let Die: On the Management of Creativity}

\section{Michael Hartmann, Désirée Laubengaier and Kai Foerstl}

question. Typically, the managers' argumentation that rejecting an idea is based on internal constraints is at odds with the open call for innovative ideas. This circumstance makes employees doubt the seriousness of the company's innovation management initiatives. They may even start labelling the established innovation management tools, typically meetings, and other approaches meant to foster the creation of new ideas, using swearwords. For example, one manager put it as follows:

"In our company, 'steering committee' is a faux-pas word." (Engineering Manager, Interview \#12)

Besides labelling established innovation management approaches using negatively connoted words, employees tell episodes of projects that were unsuccessful, make fun of failures that happen during innovation projects, or degrade outcomes of improvement initiatives as insignificant, based on the innovation management process used. We subsume and term these practices "denigration". We observed that denigration could come from the instantaneous result of rejected ideas, or be a consequence of employees over-engaging in "reluctance" during the implementation phase of their idea.

\section{Virtuous and vicious circle of managerial attempts to manage creativity}

The repercussions of managerial attempts to manage creativity impacts employees' willingness to engage in the efforts being made to foster the suggestion of novel and useful ideas. We identify a virtuous circle in which sanguinity about realized projects fosters a suggestion of ideas, and a vicious cycle that prevents actors from suggesting ideas as a result of the denigration of innovation management efforts initialized by the company. The following figure illustrates the process described above, and locates the practices identified as well as repercussions, within the framework of the "idea journey" as proposed by Perry-Smith and Mannucci (2017).

The idea journey consists of the phases "idea generation", "elaboration", "championing", and "implementation". We identified managerial attempts to manage the elaboration of ideas, that is, actions to promote the sharing of developed ideas in presentation to the review board. Further, the explored managerial attempts to champion ideas (and decide on their implementation) led to various repercussions related to the employees' commitment to the organization's innovation management efforts. Employees whose idea

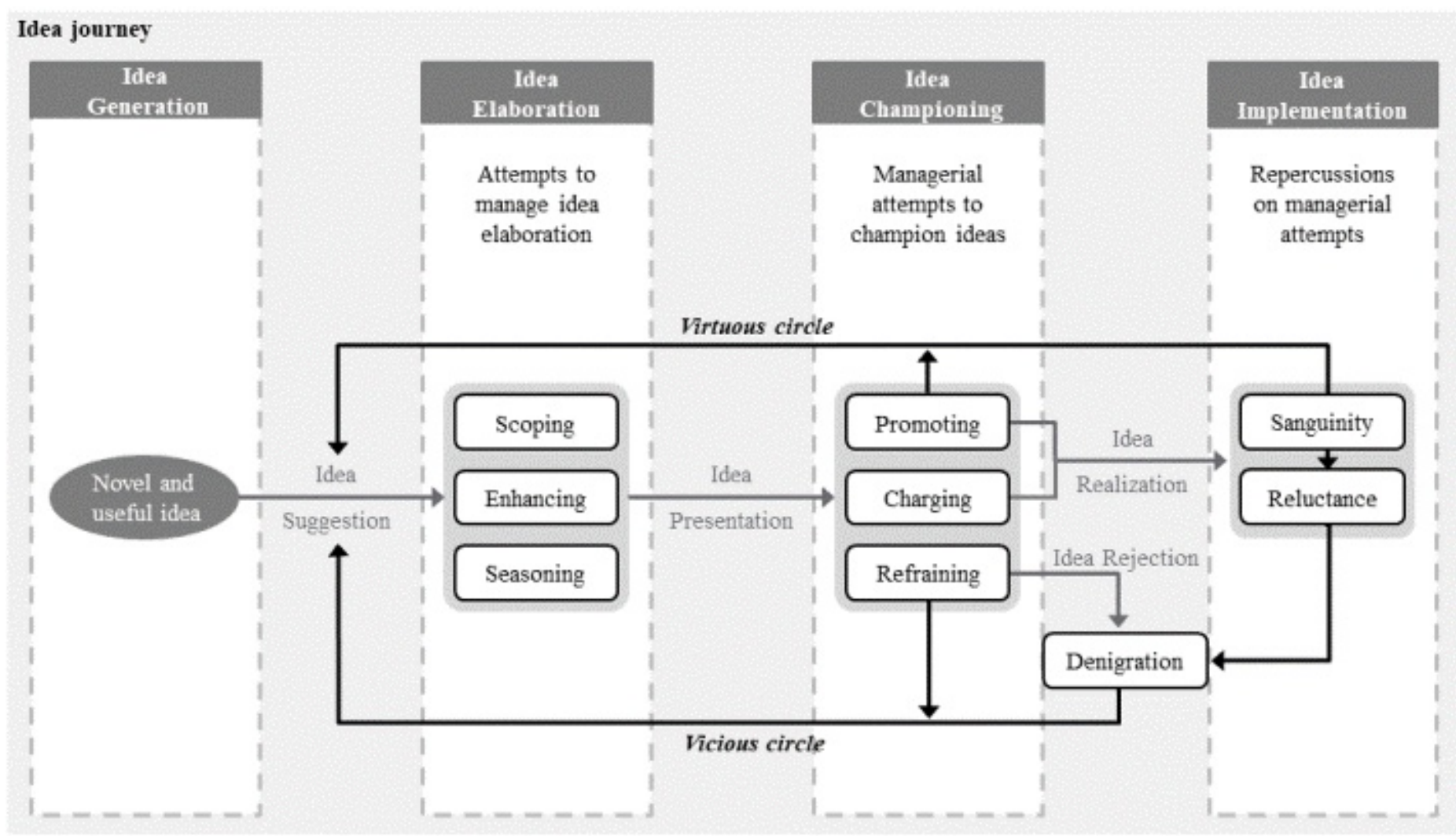

Figure 2. Virtuous and vicious circle of managerial attempts to manage creativity 


\title{
Live and Let Die: On the Management of Creativity
}

\author{
Michael Hartmann, Désirée Laubengaier and Kai Foerstl
}

is backed by the review board feel supported and communicate achievements made in a positive tone with respect to the idea they suggested. This attitude can be seen even in cases of experienced setbacks during the realization phase of the idea. Positive examples of realized projects are also highlighted by the management team as "beacons" of the company's innovation management efforts. Consequently, "promoting" and "sanguinity" have a positive effect on employees' willingness to come up with novel and useful ideas, which is why we introduce the notion of a "virtuous circle" to describe this effect.

On the other hand, employees' willingness to contribute to the organization's innovation management efforts is negatively affected once other employees start denigrating them. As described before, the way management refuses to support an idea is at odds with the attempts to manage idea elaboration, making employees doubt the fairness and transparency of the decisions made by the review board. Employees may also start questioning the authenticity of the communicated need to be more innovative due to opposing statements from senior managers involved in implementation processes. For example, a senior manager commented on their company's innovation efforts:

\section{"We can care about innovations once we are on track with our core business." (Participant observation)}

In turn, employees may start to call into question both the attempts to manage championing ideas and idea elaboration. Through denigration, the authenticity of managerial attempts to manage idea elaboration is called into question, preventing employees from suggesting (future) ideas. Furthermore, refraining from ideas that have been developed according to the required standards fuels a negative attitude towards the rationale behind innovation management initiatives. Thus, employees perceive management's commitment to innovation and the call for creative ideas as mere lip service. We call this phenomenon a "vicious circle" to describe the de-authentication of practices in managing idea elaboration (which is fuelled by refrain from proposing ideas), which disincentivizes employees from suggesting new creative ideas.

\section{Discussion and Conclusion}

We shed light on the complexities inherent in the process of generating and developing creative ideas. In particular, we reveal distinct managerial practices where actors draw on internal complexities, as well as resource constraints, to steer the development of creative ideas. We further identify dysfunctionalities inherent in such processes and find that enacting practices is constitutive for a "climate" that impacts actors' willingness to participate in innovation projects, as well as to contribute their creative ideas in the future. Thereby, we show how managers foster or impede the development of creative ideas intentionally, and also unintentionally. We propose both a virtuous and vicious cycle to explain how managerial actions impact an organization's capability to innovate. Our paper aims to contribute to the advancement of theoretical and practical knowledge on creativity and innovation management as follows.

First, our study demonstrates the usefulness of a practice lens for advancing theoretical and practical knowledge on creativity and innovation management as proposed by Crossan and Apaydin (2010). Our findings show how the capability to innovate comes into being in and through managerial interactions, rather than just ascribing it to a firm based on its past successes in implementing new and useful ideas within the organization. In doing so, we shed light on the link between individual level interactions and organizational level outcomes. Thus, we show the dynamics of daily interactions and possible spirals they produce through reinforcing mechanisms. In this vein, we present distinct practices that are key drivers for the establishment of a "climate" (Andriopoulos, 2001) that is (non-)supportive for creative performance, and we propose a vicious and a virtuous cycle to explain the inherent dynamics of the process.

Second, we follow the call of several researchers (e.g. Harrison and Rouse, 2015) to pay closer attention to the (seemingly) mundane practices that foster or impede the invention and development of new ideas in organizations. In particular, we shed light on the contradiction between managerial talk (promoting creative ideas) and action (refraining from proposed ideas). While previous research looked at the consequences that managers experience from "decoupling" talk and action (i.e. Schaefer, 2018), we examine the consequences on the employees' side, as well as the innovation management efforts that arise from managers' diverging statements and behaviours. Furthermore, while previous research by Harrison and Rouse (2015) showed the tactics that feedback givers and receivers use to develop creative prototypes, we shed light on the practices through which feedback impacts future creative performance, emphasizing the 


\section{Live and Let Die: On the Management of Creativity}

\section{Michael Hartmann, Désirée Laubengaier and Kai Foerstl}

limitations of institutional efforts to organize creativity.

Third, previous research highlighted that innovation consists of idea creation and implementation, the latter being a political process (Baer, 2012). By focusing on the practices along the idea journey proposed by PerrySmith and Mannucci (2017), we combine the different phases and show how the political process impacts idea generation, and that even participation in idea systems may turn out to be perceived as political action. While several researchers showed under which circumstances actors are more or less willing to continue contributing with creative ideas when facing negative feedback or a rejection (Kim and Kim, 2019; Piezunka and Dahlander, 2019), we extend their research and propose that actors may also engage in political actions, and start delegitimizing managerial efforts aimed at fostering innovation output.

In revealing practices that managers use in the context of creativity and innovation, we provide practical insights that can help organizations to improve their efforts in managing innovation processes. First, managers aware of the right practices and their effects can adapt their feedback behaviour to foster creativity and innovation within their team, and provide an organizational context that supports innovation. In particular, managers should pay attention that communication at different stages of the idea journey is coherent. In our case, highlighting the need for new and even radical ideas was at odds with the line of argumentation about why some proposed ideas were not realized. This, in turn, fuelled employees' doubts about the seriousness of management's efforts in fostering creativity and innovation.

Second, we recommend setting up organizational processes to facilitate open communication and allow for more flexibility in evaluating and developing creative ideas. In our case, employees had the feeling of entering unidirectional communication when engaging with the board where their ideas were finally evaluated. Although Perry-Smith and Mannucci (2017) conceptualize that idea generators may move back and forth between idea elaboration and idea championing, that is, convincing relevant people to release resources for idea implementation, our case shows that the attempt to manage creativity with designated stage gates of the idea journey, did not provide the flexibility to rework some of the ideas proposed so that they finally could pass the review board.

Regarding our empirical research design and results, our study faces some limitations, and points toward needs for future research. In particular, the design of a single case study is suitable for exploring the complexities in innovation management processes, but at the same time limits the generalizability of our study's results. Given a production facility as context for the study, where emphasis was on generating creative solutions to improve efficiency and effectiveness, we propose carrying out research in other suitable contexts, such as in product development departments or professional service firms. Furthermore, in this paper we tried to show how individual actions mount up to be constitutive for an organization's ability to come up with creative ideas by introducing the notion of a vicious and a virtuous circle. Future research might explore under which circumstances (new) employees, especially those who have not been previously involved in creativity management efforts, are more or less likely to be retracted by one or the other circle. 


\title{
Live and Let Die: On the Management of Creativity
}

\author{
Michael Hartmann, Désirée Laubengaier and Kai Foerstl
}

\section{References}

Amabile, T. M. 1988. A model of creativity and innovation in organizations. In B. M. Staw, B. M. and Cummings, L. L., Research in Organizational Behavior, 10: 123-167.

Anderson, N., Poto nik, K., and Zhou, J. 2014. Innovation and Creativity in Organizations. Journal of Management, 40 (5): 1297-1333.

Andriopoulos, C. 2001. Determinants of organisational creativity. A literature review. Management Decision, 39 (10): 834-841.

Baer, M. 2012. Putting Creativity to Work. The Implementation of Creative Ideas in Organizations. Academy of Management Journal, 55 (5): 1102-1119.

Barratt, M., Choi, T.Y., and Li, M. 2011. Qualitative Case Studies in Operations Management: Trends, Research Outcomes, and Future Research Implications. Journal of Operations Management, 29 (4): 329-342.

Crossan, M.A. and Apaydin, M. 2010. A MultiDimensional Framework of Organizational Innovation: A Systematic Review of the Literature. Journal of Management Studies, 47 (6): 1154-1191.

Eisenhardt, K.M. 1989. Building Theories from Case Study Research. Academy of Management Review, 14 (4): 532-550.

Eisenhardt, K.M. and Graebner, M.E. 2007. Theory Building from Cases: Opportunities and Challenges. Academy of Management Journal 50 (1), 25-32.

Feldman, M.S. and Orlikowski, W.J. 2011. Theorizing Practice and Practicing Theory. Organization Science, 22 (5): $1240-1253$.

Flyvbjerg, B. 2006. Five Misunderstandings About CaseStudy Research. Qualitative Inquiry, 12 (2): 219-245.

Fortwengel, J., Schüßler, E., and Sydow J. 2017. Studying Organizational Creativity as Process. Fluidity or Duality? Creativity and Innovation Management, 26 (1): $5-16$.

Garud, R., Tuertscher, P., and van de Ven, A. H. 2013. Perspectives on Innovation Processes. Academy of Management Annals, 7 (1): 775-819.

George, J. M. 2007. Creativity in Organizations. The Academy of Management Annals, 1 (1): 439-477.

Gephart Jr., R.P. 2004. Qualitative Research and the Academy of Management Journal. Academy of Management Journal, 47 (4): 454-462.

Glaser, B. and Strauss, A. 1967. The Discovery of Grounded Theory: Strategies for Qualitative Research. London: Wiedenfeld and Nicholson.

Gioia, D.A., Corley, K.G., and Hamilton, A.L. 2013. Seeking Qualitative Rigor in Inductive Research: Notes on the Gioia Methodology. Organizational Research Methods, 16 (1): 15-31.

Harrison, S. H. and Rouse, E. D. 2015. An Inductive Study of Feedback Interactions over the Course of
Creative Projects. Academy of Management Journal, 58 (2): 375-404.

Jick, T.D. 1979. Mixing Qualitative and Quantitative Methods: Triangulation in Action. Administrative Science Quarterly, 24: 602-611.

Kim, Y.J. and Kim, J. 2019. Does Negative Feedback Benefit (or Harm) Recipient Creativity? The Role of the Direction of Feedback Flow. Academy of Management Journal. DOI: 10.5465/amj.2016.1196.

Langley, A. and Abdallah, C. 2011. Templates and turns in Qualitative Studies of Strategy and Management. Research Methodology in Strategy and Management, 6: $105-140$.

Mariotto, F.L., Zanni, P.P., DeMoraes, G.H.S.M. 2014. What is the Use of a Single-Case Study in Management Research? Revista de Administracao de Empresas, 54 (4): 358-369.

Meredith, J. 1998. Building operations management theory through case and field research. Journal of Operations Management, 16 (4): 441-454.

Perry-Smith, J.E. and Mannucci, P.V. 2017. From Creativity to Innovation. The Social Network Drivers of the Four Phases of the Idea Journey. Academy of Management Review, 42 (1): 53-79.

Piezunka, H. and Dahlander, L. 2019. Idea Rejected, Tie Formed. Organizations' Feedback on Crowdsourced Ide.as. Academy of Management Journal, 62 (2): 503-550.

Popper, K.R. 1959. The Logic of Scientific Discovery. New York.

Pratt, M.G. 2009. For the Lack of a Boilerplate: Tips on Writing Up (and Reviewing) Qualitative Research. Academy of Management Journal, 52 (5): 856-862.

Schaefer, S.M. 2018. Willful Managerial Ignorance, Symbolic Work and Decoupling. A SocioPhenomenological Study of 'Managing Creativity'. Organization Studies, 12 (1): 1-21.

Siggelkow, N. 2007. Persuasion with Case Studies. Academy of Management Journal, 50 (1): 20-24.

Stuart, I., McCutcheon, D., Handfield, R., McLachlin, R., and Samson, D. 2002, Effective Case Research in Operations Management: A Process Perspective. Journal of Operations Management, 20 (5): 419-433.

Vaughan, D. 1992, Theory Elaboration: The Heuristics of Case Analysis. In What Is a Case?: Exploring the Foundations of Social Inquiry, edited by C. Ragin and H. Becker, Cambridge, MA: Cambridge University Press: 173-202.

Yin, R.K., 2014. Case Study Research. Design and Methods. 5th Ed., Sage, Los Angeles. 


\section{Live and Let Die: On the Management of Creativity}

\section{Michael Hartmann, Désirée Laubengaier and Kai Foerstl}

\section{About the Authors}

Michael Hartmann is Professor for Industrial Marketing and Sales at Coburg University of Applied Sciences and Arts, Germany. He received his PhD from European University Viadrina Frankfurt (Oder), Germany, where he joined the doctoral program „Dynamic Capabilitites and Relationships“. Before entering academia, he has been working in industry as a Key Account Manager and Business Unit Manager. In his teaching, he focuses on (industrial) marketing and personal selling. His research interest centers around the management and marketing of creative ideas and innovations in business-tobusiness settings and personal selling interactions.

Désirée Laubengaier holds a Master of Science degree in Business Management from Julius-MaximiliansUniversity of Wuerzburg, Germany. At present, she is pursuing her doctoral studies at the Politecnico di Milano, Italy. Her research interests are in the fields of innovation management, process innovation and organizational culture. She is also particularly interested in qualitative research and process studies. Her previous professional experience includes examining organizational cultural aspects of innovativeness in an industrial context.

Kai Foerstl (Dr. rer. pol. habil., EBS Business School) is Professor of Supply Chain Management and Logistics at German Graduate School of Management and Law, Heilbronn. In his research and teaching he focuses on cross-functional supply chain teams, reshoring/insourcing and sustainable global sourcing. He has been involved in publicly funded and industrial research projects in the pharmaceutical, chemical, automotive and automation industries as well as research projects involving logistics service providers and international retailers. His research has been published in leading outlets such as Journals of Supply Chain Management, Journal of Business Ethics, International Journal of Operations and Production Management, and other scholarly and managerial outlets such as Supply Chain Management Review. $\mathrm{He}$ serves on numerous editorial review boards as associate editor and reviewer.
Citation: Hartmann, M., Laubengaier, D. and Foerstl, K. 2019. Live and Let Die: On the Management of Creativity. Technology Innovation Management Review, 9(10): 16-26.

http://doi.org/10.22215/timreview/1272

(cc) BY

Keywords: Case Study; Creativity; Feedback;

Innovation Management; Qualitative Research 